\title{
Partial recovery of erythrocyte glycogen in diabetic rats treated with phenobarbital
}

C.A. da-Silva and A.A. Gonçalves
Laboratório de Eletrofisiologia e Metabolismo, Departamento de Fisiologia e Biofísica, Instituto de Biologia, Universidade Estadual de Campinas, 13083-970 Campinas, SP, Brasil

\section{Correspondence}

A.A. Gonçalves

Laboratório de Eletrofisiologia

e Metabolismo

Departamento de Fisiologia e

Biofísica

IB, UNICAMP

13083-970 Campinas, SP, Brasil

Fax: 55 (019) 239-3124

E-mail: arigon@obelix.unicamp.br

Presented at the XI Annual Meeting of the Federação de Sociedades de Biologia Experimental, Caxambu, MG, Brasil, August 21-24, 1996.

Research supported partially by CNPq (No. 521383/93-5BF) and FAEP-UNICAMP (No. 1139/94).

C.A. da-Silva was the recipient of a CAPES fellowship. This work is part of a PhD thesis presented by C.A. da-Silva. Publication supported by FAPESP.

Received April 23, 1996 Accepted January 29, 1997

\begin{abstract}
Erythrocytes may play a role in glucose homeostasis during the postprandial period. Erythrocytes from diabetic patients are defective in glucose transport and metabolism, functions that may affect glycogen storage. Phenobarbital, a hepatic enzyme inducer, has been used in the treatment of patients with non-insulin-dependent diabetes mellitus (NIDDM), increasing the insulin-mediated glucose disposal. We studied the effects of phenobarbital treatment in vivo on glycemia and erythrocyte glycogen content in control and alloxan-diabetic rats during the postprandial period. In control rats (blood glucose, 73 to $111 \mathrm{mg} / \mathrm{dl}$ in femoral and suprahepatic veins) the erythrocyte glycogen content was $45.4 \pm 1.1$ and $39.1 \pm 0.8 \mu \mathrm{g} / \mathrm{g} \mathrm{Hb}$ (mean $\pm \mathrm{SEM}, \mathrm{N}=4$ 6 ) in the femoral artery and vein, respectively, and $37.9 \pm 1.1$ in the portal vein and $47.5 \pm 0.9$ in the suprahepatic vein. Diabetic rats (blood glucose, $300-350 \mathrm{mg} / \mathrm{dl})$ presented low $(\mathrm{P}<0.05)$ erythrocyte glycogen content, i.e., $9.6 \pm 0.1$ and $7.1 \pm 0.7 \mu \mathrm{g} / \mathrm{g} \mathrm{Hb}$ in the femoral artery and vein, respectively, and $10.0 \pm 0.7$ and $10.7 \pm 0.5$ in the portal and suprahepatic veins, respectively. After 10 days of treatment, phenobarbital $(0.5 \mathrm{mg} / \mathrm{ml}$ in the drinking water $)$ did not change blood glucose or erythrocyte glycogen content in control rats. In diabetic rats, however, it lowered $(\mathrm{P}<0.05)$ blood glucose in the femoral artery (from $305 \pm 18$ to $204 \pm 45 \mathrm{mg} / \mathrm{dl}$ ) and femoral vein (from $300 \pm 11$ to $174 \pm 48 \mathrm{mg} / \mathrm{dl}$ ) and suprahepatic vein (from $350 \pm 10$ to $174 \pm 42 \mathrm{mg}$ / dl), but the reduction was not sufficient for complete recovery. Phenobarbital also stimulated the glycogen synthesis, leading to a partial recovery of glycogen stores in erythrocytes. In treated rats, erythrocyte glycogen content increased to $20.7 \pm 3.8 \mu \mathrm{g} / \mathrm{g} \mathrm{Hb}$ in the femoral artery and $30.9 \pm 0.9 \mu \mathrm{g} / \mathrm{g} \mathrm{Hb}$ in the suprahepatic vein $(\mathrm{P}<0.05)$. These data indicate that phenobarbital activated some of the insulin-stimulated glucose metabolism steps which were depressed in diabetic erythrocytes, supporting the view that erythrocytes participate in glucose homeostasis.
\end{abstract}

Key words

- Erythrocytes

- Glycogen

- Phenobarbital

- Diabetes mellitus

- Erythrocyte metabolism

- Alloxan 
Studies of carbohydrate metabolism and glucose transport suggest that erythrocytes play a role in glucose homeostasis. Similar to other cells, they are equipped with the glucose transporter identified as GLUT1 which is not regulated by hormones. GLUT1 has a low $\mathrm{K}_{\mathrm{m}}$ for glucose $(\sim 2 \mathrm{mM})$ when assayed by zero-trans uptake. In situ, it exhibits an asymmetric pattern of transport, with a 4-fold higher $\mathrm{K}_{\mathrm{m}}$ for efflux compared to influx (1). The glucose transporter of erythrocyte may represent $3.5 \%$ of membrane proteins (2). For energy production, erythrocytes require glycolysis which is very low $\left(1.1 \mathrm{mmol} \mathrm{h}^{-1} \mathrm{l}^{-1}\right)$ in normoglycemic humans (3). However, the uptake of glucose exceeds by more than twelve thousand times their metabolic requirement (4). This excess is distributed to the periphery, which contributes to glucose homeostasis, especially during the postprandial period. Accordingly, under hyperglycemic conditions, glucose is taken up and released when glycemia falls below normal values $(5,6)$.

Glucose is stored in erythrocytes as glycogen. Enzymes for glycogen synthesis and breakdown have long been recognized in normal erythrocytes $(7,8)$. The $b$ isoform of glycogen synthase (UDP-glucose-glycogen glycosyl transferase), the only form present in erythrocytes, is exclusively activated by glucose-6-phosphate. Following incubation at $37^{\circ} \mathrm{C}$, the glycogen content of erythrocytes from normal rats is linearly correlated with increasing extracellular glucose concentrations (6). Glycostatic functions are affected in diabetic erythrocytes. Reduction of glucose transporter function (9), impairment of glucose utilization and reduction of glucose-6-phosphate production (10) have been reported. During preliminary studies, we found that erythrocytes from alloxan-diabetic rats have a low glycogen content, either when freshly isolated or when incubated with increasing glucose concentrations. All of these changes reinforce the idea of a role of erythrocytes in glucose homeostasis.
Carbohydrate and drug metabolism are linked in hepatocytes. Several studies have shown that an increased flux of glucose through the pentose pathway improved glucose metabolism. Phenobarbital, an inducer of glucuronyltransferase, several forms of cytochrome P-450 and many mixed-function oxidases have been employed $(11,12)$ to decrease the plasma insulin concentration without changing fasting glucose levels and to increase the glucose disposal rate in healthy non-diabetic subjects. Combined therapy utilizing phenobarbital and sulfonylurea was beneficial to non-insulin-dependent diabetic patients, enhancing the insulin-mediated glucose disposal (13).

Since hepatocytes and erythrocytes, as participants in glucose homeostasis, share some properties related to glucose transport and glycogen storage, we studied the effects of phenobarbital treatment in vivo on glycemia and glycogen content of erythrocytes from normal and diabetic rats.

Adult male Wistar rats (3 months old) were obtained from Centro de Bioterismo, UNICAMP, Brazil, and housed at $22 \pm 2^{\circ} \mathrm{C}$, under a 12-h light/dark cycle (lights on, 6:00 a.m.), receiving laboratory chow and water ad libitum. One week later, their hematological parameters (blood cell count, hematocrit, hemoglobin concentration and glycemia) were determined and found to be normal. Diabetes was induced by alloxan (40 $\mathrm{mg} / \mathrm{kg}$ body weight, $i v$ ) in rats under ether anesthesia and confirmed by the appearance of glycosuria. One week later, control and diabetic groups were divided into two further groups; one continued to receive plain tap water (control and diabetic rats) and the other received phenobarbital $(0.5 \mathrm{mg} / \mathrm{ml}$, for 10 days) in the drinking water (treated control and treated diabetic rats). Experiments were performed with fed rats, $3 \mathrm{~h}$ after the light was turned on and $1 \mathrm{~h}$ after food removal. Rats were anesthetized with sodium pentobarbital and 30 min later the right femoral vein and artery were exposed and succes- 
sive blood samples $(0.5 \mathrm{ml})$ were collected from them. After laparotomy, blood was also collected from the portal and suprahepatic veins, about 60 to $65 \mathrm{~s}$ after exposure of the femoral artery. After centrifugation, plasma was separated and used for determination of glycemia. Erythrocytes were resuspended two times in $0.9 \%$ saline solution and the supernatant was discarded to avoid leukocyte contamination. Plasma glucose concentration was measured by an enzymatic method (Celm-Reactoclin) at $505 \mathrm{~nm}$. Hemoglobin concentration was measured from a $20-\mu \mathrm{l}$ aliquot of erythrocytes at 540 $\mathrm{nm}$ (Labtest). For the measurement of glycogen content, a 200- $\mu$ laliquot of erythrocytes was processed according to the method of Farquharson et al. (14) which has a sensitivity of $0.1 \mu \mathrm{g}$ and allows $90 \%$ glycogen recovery, with a detection limit of $5 \mu \mathrm{g} / \mathrm{g} \mathrm{Hb}$. Amyloglycosidase, oyster glycogen and NAD were obtained from Sigma (St. Louis, MO). All other reagents were analytical grade. Results are reported as mean $\pm \mathrm{SEM}, \mathrm{N}=4$ 6 . The data for the arteriovenous and portal and suprahepatic veins were analyzed statistically by the paired Student $t$-test. The differences between groups were analyzed statistically by one-way ANOVA followed by the Tukey test.

Table 1 shows the glycemia of control, diabetic and phenobarbital-treated rats. Glycemia varied in control rats according to the vessel sampled, showing an expected arteriovenous difference of $25 \%(\mathrm{P}<0.05)$. These results are compatible with peripheral glucose utilization and in agreement with Guarner and Alvarez-Buylla (6). Also, we measured the difference between the portal and suprahepatic veins, with glycemia increasing by $15 \%(\mathrm{P}<0.05)$ after blood had crossed the liver. Glycemia was three times higher in alloxan-diabetic rats than in the control group and showed no arteriovenous difference. However, glycemia in the suprahepatic vein was still higher than in the portal vein $(17 \%, \mathrm{P}<0.05)$ due to the known
Table 1 - Effect of phenobarbital on serum glucose concentration of alloxan-diabetic rats.

Treated rats received phenobarbital $(0.5 \mathrm{mg} / \mathrm{ml})$ for 10 days in drinking water. Data are reported as mean $\pm \mathrm{SEM}$ in $\mathrm{mg} / \mathrm{dl} ; \mathrm{N}=6$ for control, treated control and diabetic rats and $\mathrm{N}=4$ for treated diabetic rats. Data were analyzed statistically by ANOVA, followed by the Tukey test. ${ }^{*} \mathrm{P}<0.05$ compared to control and treated control groups and $+P<0.05$ compared to untreated diabetic group.

\begin{tabular}{lcccc}
\hline Groups & $\begin{array}{c}\text { Femoral } \\
\text { artery }\end{array}$ & $\begin{array}{c}\text { Femoral } \\
\text { vein }\end{array}$ & $\begin{array}{c}\text { Portal } \\
\text { vein }\end{array}$ & $\begin{array}{c}\text { Suprahepatic } \\
\text { vein }\end{array}$ \\
\hline Control & $97 \pm 12.0$ & $73 \pm 3.4$ & $96 \pm 5.8$ & $111 \pm 4.3$ \\
Treated control & $97 \pm 2.9$ & $89 \pm 4.1$ & $87 \pm 2.9$ & $97 \pm 3.0$ \\
Diabetic & $305 \pm 18.0^{*}$ & $300 \pm 11.0^{*}$ & $300 \pm 19.0^{*}$ & $350 \pm 10.0^{*}$ \\
Treated diabetic & $204 \pm 45.0^{*+}$ & $174 \pm 48.0^{*+}$ & $261 \pm 46.0^{*}$ & $174 \pm 42.0^{*+}$
\end{tabular}

increased liver glucose output in the absence of insulin. Phenobarbital treatment reduced glycemia in the femoral artery and vein and suprahepatic vein of diabetic rats $(\mathrm{P}<0.05)$, although not enough to restore control values. The reduction in phenobarbital-induced glycemia may correspond to a) an improvement in peripheral glucose utilization as shown by the $14.7 \%$ arteriovenous difference; b) a reduction of glucose output from the liver $(\mathrm{P}<0.05)$ and $\mathrm{c})$ an increase in glucose uptake by the liver, erythrocytes and skeletal muscles and consequently, an increase in glycogen synthesis (as will be shown below). Our results agree with studies conducted on non-insulin-dependent diabetic patients (13) and streptozotocin-diabetic rats (15), showing that phenobarbital improved the sensitivity of individuals to insulin by reducing the fasting glycemia and increasing the insulin-mediated glucose metabolism. The latter effect (13) was closely correlated with the rate of plasma antipyrine clearance, an index of liver microsomal enzyme activity, suggesting that peripheral glucose utilization and the liver microsomal system may share common regulators. Thus, stimulation of the liver microsomal system by phenobarbital may be one of the key steps for the reduction of glycemia in treated diabetic rats.

Table 2 shows the glycogen content of 
Table 2 - Effect of phenobarbital on erythrocyte glycogen content of control and alloxan-diabetic rats.

Treated rats received phenobarbital $(0.5 \mathrm{mg} / \mathrm{ml})$ for 10 days in drinking water. Data are reported as mean \pm SEM in $\mu \mathrm{g} / \mathrm{g}$ hemoglobin; $\mathrm{N}=6$ for control, treated control and diabetic rats and $\mathrm{N}=4$ for treated diabetic rats. Data were analyzed statistically by ANOVA, followed by the Tukey test. ${ }^{*} \mathrm{P}<0.05$ compared to control group and $+\mathrm{P}<0.05$ compared to untreated diabetic group.

\begin{tabular}{lcccc}
\hline Groups & $\begin{array}{c}\text { Femoral } \\
\text { artery }\end{array}$ & $\begin{array}{c}\text { Femoral } \\
\text { vein }\end{array}$ & $\begin{array}{c}\text { Portal } \\
\text { vein }\end{array}$ & $\begin{array}{c}\text { Suprahepatic } \\
\text { vein }\end{array}$ \\
\hline Control & $45.4 \pm 1.1$ & $39.1 \pm 0.8$ & $37.9 \pm 1.1$ & $47.5 \pm 0.9$ \\
Treated control & $44.7 \pm 2.6$ & $38.9 \pm 3.2$ & $37.0 \pm 5.7$ & $46.8 \pm 1.4$ \\
Diabetic & $9.6 \pm 0.1^{*}$ & $7.1 \pm 0.7^{*}$ & $10.0 \pm 0.7^{*}$ & $10.7 \pm 0.5^{*}$ \\
Treated diabetic & $20.7 \pm 3.8^{+}$ & $9.2 \pm 2.8^{*}$ & $12.6 \pm 2.7^{*}$ & $30.9 \pm 0.9^{*+}$
\end{tabular}

erythrocytes from control, diabetic and phenobarbital-treated rats. Our results showed differences in erythrocyte glycogen content between the femoral artery and vein $(\sim 14 \%$, $\mathrm{P}<0.05)$ of both control and treated control rats and between the portal and suprahepatic vein $(26 \%, \mathrm{P}<0.05)$ of controls alone. Diabetic rats had a low glycogen content, about $1 / 4$ of the control. Following phenobarbital treatment, the erythrocyte glycogen content increased in the femoral artery and suprahepatic vein $(\mathrm{P}<0.05)$, but the recovery was incomplete.

These results are in agreement with the changes in glycemia induced by phenobarbital treatment (Table 1) and partially account for the reduction of blood glucose. Our results may be compared to those reported for the rectus muscle of streptozotocin-diabetic rats (15) in which phenobarbital treatment induced an increase in $\left[3-{ }^{3} \mathrm{H}\right]$ glucose incorporation into glycogen. Both effects may be a consequence of the phenobarbital-induced increase in insulin-mediated glucose utilization. Phenobarbital is a classical activator of the hepatic microsomal enzyme system whose terminal component is cytochrome $\mathrm{P}$ 450. This system is involved in the metabolism of a variety of drugs, steroids and other endogenous and exogenous compounds. It is activated by NADPH and uridine diphosphate whose increase depends on the activity of glucose-6-phosphate dehydrogenase and 6-phosphogluconate dehydrogenase via the pentose pathway and cytosolic malic enzymes (16). Phenobarbital also increases hepatic glucokinase and hexokinase, enzymes that phosphorylate glucose, and decreases the activity of glucose-6-phosphatase, which controls glucose release from the liver (17). Phenobarbital has similar effects on skeletal muscle from normally fed rats. In this preparation, a close correlation was found between glucose-6-phosphate concentrations, determined as percent glycogen synthase in the active I form whose conversion is insulin dependent, and phosphatase activity (18). The increase in glycogen content in erythrocytes from diabetic rats treated with phenobarbital may be the consequence of an increase in glucose-6-phosphate concentration which stimulates glycogen synthase b. Our results suggest that erythrocytes play a role in glucose homeostasis, contributing to its storage and distribution and demonstrate that the treatment with phenobarbital, a hepatic enzyme inducer, partially restored erythrocyte glycogen content and reduced glycemia in alloxan-diabetic rats. 


\section{References}

1. Burant CF, Sivitz WI, Fukumoto $H$, Kayano T, Nagamatsu S, Seino S, Pessin JE \& Bell GI (1991). Mammalian glucose transporters: structure and molecular regulation. Recent Progress in Hormone Research, 47: 1-41.

2. Zoccoli MA, Boldwin SA \& Lienhard GE (1978). Monosaccharide transport system of the human erythrocyte. Journal of Biological Chemistry, 253: 69213-69230.

3. Rapoport S (1968). The regulation of glycolysis in mammalian erythrocytes. Essays in Biochemistry, 4: 69-103.

4. Jacquez JA (1984). Red blood cell as glucose carrier: significance for placental and cerebral glucose transfer. American Journal of Physiology, 246: 289-298.

5. Ferranini E \& Bjorkman O (1986). Role of red blood cells in the regulation of blood glucose levels in man. Diabetes, 35 (Suppl 1): 39 (Abstract).

6. Guarner V \& Alvarez-Buylla R (1989). Erythrocyte and glucose homeostasis in rats. Diabetes, 38: 410-415.

7. Hers HG, Verhue W \& van Hoof F (1967). The determination of amylo-1,6-glucosidase. European Journal of Biochemistry, 2: 256-264.

8. Moses SW, Bashan N \& Gutman A (1972). Properties of glycogen synthetase in erythrocytes. European Journal of Biochemistry, 30: 205-210.
9. Garvey WT, Hueckstedt TP \& Olefsky JM (1987). Glucose and insulin co-regulate the glucose transport system in primary cultured adipocytes. A new mechanism of insulin resistance. Diabetes, 36 (Suppl 1): 84 (Abstract)

10. Rapin JR, Lespinasse C, Yoa R \& Wiernsperger N (1991). Erythrocyte glucose consumption in insulin-dependent diabetes: effect of metformin in vitro. Diabete et Metabolisme, 14: 164-167.

11. Lahtela JT, Sarkka P \& Sotaniemi EA (1984). Phenobarbital treatment enhances insulin mediated glucose metabolism in man. Research Communications in Chemical Pathology and Pharmacology, 44: 215226.

12. Lahtela JT, Gachalyi B \& Eksyma S (1986). The effect of liver microsomal enzyme inducing and inhibiting drugs on insulin mediated glucose metabolism in man. British Journal of Clinical Pharmacology, 21: 19-26.

13. Lahtela JT, Arranto AJ \& Sotaniemi EA (1985). Enzyme inducers improve insulin sensitivity in non-insulin-dependent diabetic subjects. Diabetes, 34: 911-916.

14. Farquharson J, Jamieson EC, MacPhee GB \& Logan RW (1990). A new sensitive microassay for the measurement of erythrocyte glycogen. Clinica Chimica Acta, 187: 89-94.
15. Venkatsen N, Davidson MB, Simsolo RB \& Kern PA (1994). Phenobarbital treatment enhances insulin-mediated glucose metabolism and improves lipid metabolism in the diabetic rat. Metabolism: Clinical and Experimental, 43: 348-356.

16. Thurman RG \& Kauffman FC (1980). Factors regulating drug metabolism in the intact hepatocytes. Pharmacological Reviews, 31: 229-251.

17. Karvonen I, Stengard JH \& Huupponen R (1989). Effects of enzyme induction therapy on glucose and drug metabolism in obese mice model of non-insulin dependent diabetes mellitus. Diabetes Research, 10: 85-92.

18. Villar-Palasi C (1995). Effect of glucose phosphorylation on the activation by insulin of skeletal muscle glycogen synthase. Biochimica et Biophysica Acta, 1244: 203208. 